\title{
Abstracts
}

\section{Economics and the Care of the Elderly}

Ken Wright

\author{
Michael Connoly, Integrating health and social services: has the Northern \\ Ireland experiment succeeded? Public Money, 4, (1985), 4, 25-28.
}

Reform in local government and health services was much in vogue during the ig6os in Great Brtain, and in Northern Ireland, unlike mainland Britain, an integrated structure was set up in 1972 for health and personal social services. The reorganisation was designed to 'facilitate the planning and delivery of more efficient, cost-effective and comprehensive services in an integrated basis for the people of Northern Ireland'. The structure was meant to lead to comprehensive planning, interprofessional co-operation and administrative efficiency.

In 1975 the elderly were singled out as a priority group for planning future expenditure which would be used to develop health and social care and expand geriatric and psycho-geriatric hospital accommodation. In the eight years that followed 22 homes for the elderly and 5 for the confused elderly were provided while 7 purpose-built geriatric units provided $54^{\circ}$ beds. Some 200 places in geriatric day centres have been provided and there was an increase in the community health services and an expansion of the home help service.

It is not at all clear that the elderly have benefited from the integration of health and personal social services. There could still appear to be a much greater degree of hospitalisation of the elderly in Northern Ireland than in the UK as a whole. There is some evidence that $25-30 \%$ of patients in geriatric and general practitioner beds did not need in-patient care. However compared with other priority groups such as mentally handicapped and mentally ill people, the elderly did reasonably well out of the developments between 1975 and 1983 .

The 1975 policy document laid much emphasis on the importance of developing a comprehensive planning system but the early attempts to achieve this were unsuccessful. One major problem is that the planning has focused narrowly on capital development, it has been concerned with the provision of buildings rather than care. This problem has been exacerbated by the lack of inter-professional cooperation which has contributed to the imbalance of service delivery to elderly people. On the positive side the integrated approach has 
witnessed the improvement in administrative efficiency and a reduction in the inter-departmental bargaining for real and financial resources.

Overall the integrated structure has offered some improvements but has had little impact on service delivery to the community. The planning process shows little evidence of being influenced by the integrated structure and there is little in the way of programme planning. The system may need more time to prove its worth but unless improvements in the planning process occur soon, many people are going to lose patience with the integrated approach.

\section{GOMMENT}

This assessment of an integrated approach to planning and providing health and social services to the elderly and other health care priority groups makes disappointing reading. It seems that the joint budgeting approach has succeeded in cutting through some of the most inefficient forms of bargaining for resources but that the planning process has not been able to take advantage of this. The over-emphasis on capital provision at the expense of planning an efficient comprehensive community service is particularly disappointing. A more efficient allocation of resources would be expected from a system which discourages separate departments from passing on its budgetary responsibilities to others, but the performance of this system so far suggests that it is the acceptance of increased expenditure and its use in capital spending that is failing to provide the desired allocation of resources for the care of the elderly.

Jill Tuffnell, Facing up to the needs of the elderly. Local Government Policy Making, I I (1984), 2, I 3-19.

This article is concerned with the difficulties of preparing and approving the plans to meet the challenge of providing satisfactory care for elderly people in their own homes in the next two years in Cambridgeshire.

Cambridgeshire in common with many English counties is facing an increase in the group of people aged 75 years or over. Whereas nationally the expected increase between $198 \mathrm{I}$ and $\mathrm{I} 996$ is $24 \%$ in Cambridgeshire the increase is expected to be $35 \%$. The demand for services is linked to several factors, for example the number of people living alone, poor housing conditions and limited access to a satisfactory public transport system. 
Against this background of growing demand, many public agencies are faced with tight financial constraints. East Anglia is one of the few regions with an increased health care budget and its real growth in expenditure over the planning period is between 0.94 and $1.6 \%$. This is not sufficient to cope with the $2 \%$ increase necessary to meet the demands of the growing number of elderly people. Resources for the care of the elderly will have to come from reduced service provision for other groups. Constraints on local authority services are equally stringent and recent changes in the grants made to local authorities by the central government will make it difficult to expand services as required.

Planning services involves a multiplicity of agencies, health authorities, family practitioner committees, local authorities at county and district level, housing associations and voluntary organisations. Each of these agencies is financed from different funds and works to different budget constraints. Both the planning machinery and the maze of financial flows make it difficult to develop a comprehensive community care service for the elderly. As the article states, 'in the current financial climate, where Housing Associations can plan only one year at a time, Local Authority capital controls can be altered 3 months into a financial year, and Health Authorities can face I \% budget cut backs without warning, only the most conservative, robust planning can survive. Inter-agency co-operation requires inter alia an agreed programme of research to identify needs; a much simplified planning system; common planning horizons for the agencies involved; and some form of joint budget, possibly a development of Joint Funding or involving pooling of resources of the agencies involved.'

COMMENT

This article reflects some of the concern with which practitioners presently view the planning and delivery of services for the care of the elderly. In contrast to the integrated system in Northern Ireland, the English health care planning system is suffering from the splintering of administrative and budgetary responsibility, hence the plea for an integrated 'pooling of resources' approach. Although the above article from the Northern Ireland experience is rather pessimistic, it seems that the English system would benefit from a co-ordinated approach to financing health, housing and social services for the elderly. The English system as represented in this article appears to have overcome the major problems of inter-professional rivalry that presently bedevil the Northern 
Ireland situations and it is a pity that planning is now being hindered by a system of cash limited budgets which discourage inter-agency innovation and the development of a satisfactory set of services for the care of the elderly.

Centre for Health Economics, University of York

\section{Social Work and Social Services}

\section{David Challis}

Pinkston, E. M. and Linsk, N. L., 'Behavioural family intervention with the impaired elderly'. Gerontologist, 24 (1984), 576-83.

There is at present a poorly developed literature in the social work field based upon approaches to help families cope with the variety of behavioural problems encountered in seriously impaired elderly relatives. The authors sought to investigate whether behavioural training procedures could be an effective means of enabling families to most effectively manage these problems at home.

Twenty-one people and their families participated in the study. These cases were selected on criteria of being over 6o, suffering physical or mental disability and exhibiting one of a range of behavioural difficulties. The intervention techniques used were concerned to increase the desired positive behaviours in both elderly person and caregiver whilst reducing non-satisfying behaviours. Care was taken where necessary to redefine problems into positive behaviours requiring development or commencement rather than negative behaviours requiring extinction. The most frequently adopted approaches were reinforcement such as differential attention or praise for specific behaviours and prompts or stimulus commands such as relating behaviour to specific prompts, cues or circumstances. A contract based technique was used to implement the agreed programmes with clients and caregivers.

The effectiveness of the interventions was evident in the improvements observed in a high proportion of behaviours in self care, social activities, negative activities, negative verbal behaviour and positive behaviour. This was retained at six months follow-up for all aspects of positive behaviour. Negative behaviour, especially verbal behaviour, was less improved. Consumer surveys suggested that behavioural approaches were felt to be helpful by caregivers, increasing their understanding of elderly people's problems. 